\section{Mössbauer and magnetic studies of FeCoNiCuNbSiB nanocrystalline alloys}

\begin{abstract}
Nanocrystalline $\mathrm{Fe}_{80-x-y} \mathrm{Co}_{x} \mathrm{Ni}_{y} \mathrm{Cu}_{1} \mathrm{Nb}_{3} \mathrm{Si}_{4} \mathrm{~B}_{12}$ alloys were prepared by the annealing of amorphous ribbons. Primary crystallization of the alloys annealed at temperatures of between 500 and $550^{\circ} \mathrm{C}$ was studied by X-ray diffraction and Mössbauer spectroscopy. Magnetic properties of the alloys were investigated using a hysteresis loop tracer and vibrating sample magnetometer. The annealed ribbons are composed of a two-phase nanostructure consisting of bcc Fe-based grains embedded in an amorphous matrix. Conversion electron Mössbauer spectroscopy (CEMS) measurements reveal a more advanced crystallization process in the surface layers when compared with the volume of the ribbons. The degree of saturation magnetization of the nanocrystalline alloys is of about $1.5 \mathrm{~T}$. The coercive field varies from 1.0 to $6.5 \mathrm{~A} / \mathrm{m}$ and peaks at an annealing temperature of $525^{\circ} \mathrm{C}$. Magnetic softening of the nanocrystalline alloys observed after annealing at $550^{\circ} \mathrm{C}$ is correlated with a volume fraction of the nanocrystalline bcc phase.
\end{abstract}

Keywords: amorphous ribbons $\bullet$ nanocrystalline alloys $\bullet$ Mössbauer spectroscopy $\bullet$ soft magnetic properties

\section{A. Grabias ${ }^{\bowtie}$, M. Kopcewicz}

Institute of Electronic Materials Technology,

133 Wólczyńska Str., 01-919 Warsaw, Poland,

Tel.: +48 22639 5547, Fax: +48 22864 5496,

E-mail: agnieszka.grabias@itme.edu.pl

V. Basykh, J. Ferenc, G. Cieślak, T. Kulik

Faculty of Materials Science and Engineering,

Warsaw University of Technology,

141 Wołoska Str., 02-507 Warsaw, Poland

Received: 15 July 2016

Accepted: 7 November 2016

\section{Introduction}

Nanocrystalline Fe-based alloys, obtained by controlled, partial crystallization of amorphous precursors, are magnetic materials which exhibit very soft magnetic properties combined with low core loss, which is favourable for applications, e.g. in energy efficient transformers [1]. Classic nanocrystalline alloys, such as FINEMET $\left(\mathrm{Fe}_{73.5} \mathrm{Cu}_{1} \mathrm{Nb}_{3} \mathrm{Si}_{13.5} \mathrm{~B}_{9}\right)$ [2] or NANOPERM-type (e.g. $\mathrm{Fe}_{90} \mathrm{Zr}_{7} \mathrm{~B}_{3}$ ) [3], are characterized by the coercive fields of 0.7 and $5.8 \mathrm{~A} / \mathrm{m}$, and the saturation magnetizations of 1.2 and $1.7 \mathrm{~T}$, respectively. The soft magnetic properties of these alloys are related to vanishing macroscopic magnetocrystalline anisotropy and low levels of magnetostriction, which are sensitive to the composition and size of the nanocrystals as well as their volume fractions in the ferromagnetic amorphous matrices $[4,5]$. This relationship between magnetic properties and nanostructure can be controlled by selecting the appropriate chemical composition of the alloy and annealing conditions.

While searching for soft magnetic materials that exhibit high degrees of saturation magnetization, amorphous $\mathrm{FeCoNiCuNbSiB}$ alloys containing large amounts of ferromagnetic transition metals (80 at.\%) were identified. Silicon, boron and, to some extent, nickel and cobalt facilitate the ability of the alloys to form glass. The addition of $\mathrm{Cu}$ and $\mathrm{Nb}$ favour the nanocrystallization process. The aim 
of this work is to study the influence of the thermally induced nanocrystallization process on the soft magnetic properties of $\mathrm{Fe}_{80-x-y} \mathrm{Co}_{x} \mathrm{Ni}_{y} \mathrm{Cu}_{1} \mathrm{Nb}_{3} \mathrm{Si}_{4} \mathrm{~B}_{12}$ alloys.

\section{Experimental details}

Amorphous $\mathrm{Fe}_{80-x-y} \mathrm{Co}_{x} \mathrm{Ni}_{y} \mathrm{Cu}_{1} \mathrm{Nb}_{3} \mathrm{Si}_{4} \mathrm{~B}_{12}$ alloys, where $x=2,3$ or 6 at. $\%$, and $y=2$ or 3 at. $\%$, were prepared by the melt-spinning technique. The ribbons were about $2 \mathrm{~mm}$ wide and $18-25 \mu \mathrm{m}$ thick. The amorphous ribbons exhibited the two-step crystallization process, as the differential scanning calorimetry (DSC) measurements revealed. In order to induce partial crystallization, the samples were annealed for $1 \mathrm{~h}$ in a vacuum at temperatures of between 500 and $550^{\circ} \mathrm{C}$, which correspond to the range in which primary crystallization (the first stage) occurs. Structural characterization of the as-quenched and annealed samples was performed by X-ray diffraction (XRD) using $\mathrm{CuK}_{\alpha}$ radiation and by Mössbauer spectroscopy using a ${ }^{57} \mathrm{Co}(\mathrm{Rh})$ source exhibiting an activity of about $25 \mathrm{mCi}$. Surface layers of the ribbons at a depth of about $100 \mathrm{~nm}$ were characterized by conversion electron Mössbauer spectroscopy (CEMS). Both sides of the ribbons were measured: (i) wheel side (matt) that was in contact with the spinning copper wheel while the ribbons were cast, and (ii) "air" side (shiny) that was not in contact with the wheel. The spectra were fitted using the NORMOS-DIST program. Relative fractions of the spectral components were calculated as a ratio of the area of the relevant subspectrum to the total spectral area, assuming similar Debye-Waller factors for each subspectrum. Magnetic properties of the alloys were studied by the measurement of hysteresis loops at room temperature using a hysteresis loop tracer $\left(H_{\max }=670 \mathrm{~A} / \mathrm{m}\right)$ and vibration sample magnetometer (VSM, $\left.H_{\max }=1.6 \mathrm{MA} / \mathrm{m}\right)$. The coercive field strength and the saturation magnetization were determined as main features characterizing the magnetic properties.

\section{Results}

Representative X-ray diffraction patterns of the as-quenched and annealed $\mathrm{Fe}_{80-x-y} \mathrm{Co}_{x} \mathrm{Ni}_{y} \mathrm{Cu}_{1} \mathrm{Nb}_{3} \mathrm{Si}_{4} \mathrm{~B}_{12}$ alloys are shown in Fig. 1 for $x=6$ and $y=2$. Diffraction patterns obtained for both sides of the as-quenched $\mathrm{Fe}_{72} \mathrm{Co}_{6} \mathrm{Ni}_{2} \mathrm{Cu}_{1} \mathrm{Nb}_{3} \mathrm{Si}_{4} \mathrm{~B}_{12}$ ribbon consist of a broad "halo" originating from an amorphous phase. A minor peak observed at $2 \theta \approx 65^{\circ}$ resulted from the presence of some bcc Fe inclusions, indicating a (200) texture of this crystalline phase. Annealing at temperatures of between 500 and $550^{\circ} \mathrm{C}$ induced primary crystallization as observed in Fig. 1 by the appearance of diffraction lines at $44.7^{\circ}$ and $65.2^{\circ}$, which resulted from a bcc Fe-based nanocrystalline phase. By using the Scherrer equation, the average crystallite sizes were roughly estimated to be below $25 \mathrm{~nm}$.

The degree of amorphism of the as-quenched $\mathrm{Fe}_{72} \mathrm{CO}_{6} \mathrm{Ni}_{2} \mathrm{Cu}_{1} \mathrm{Nb}_{3} \mathrm{Si}_{4} \mathrm{~B}_{12}$ ribbon is determined by the

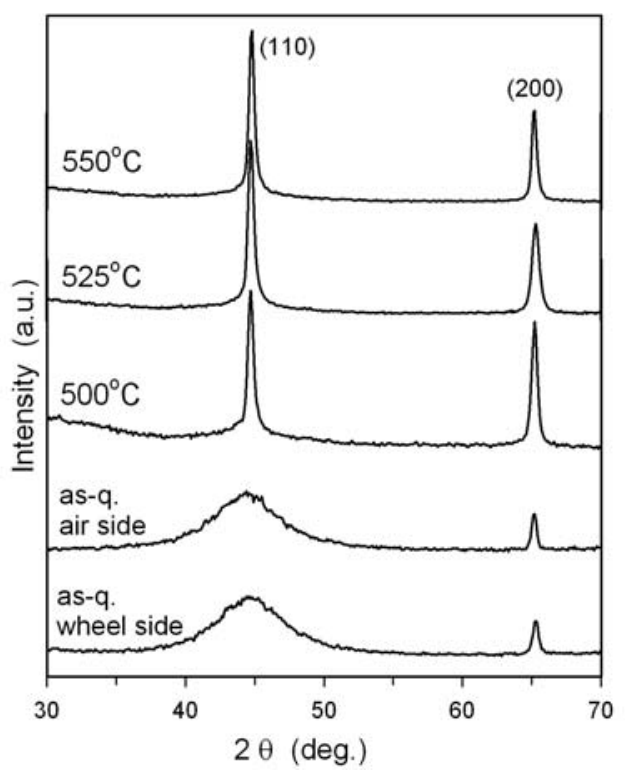

Fig. 1. X-ray diffraction patterns of the $\mathrm{Fe}_{72} \mathrm{Co}_{6} \mathrm{Ni}_{2} \mathrm{Cu}_{1} \mathrm{Nb}_{3} \mathrm{Si}_{4} \mathrm{~B}_{12}$ alloy in the as-quenched and annealed states.

Mössbauer spectra recorded for the entire volume (the transmission spectra) and for the surfaces of the ribbon (CEMS spectra of the wheel and "air" sides), which are shown in Fig. 2a and Figs. 2b-c, respectively. These spectra consist of broad magnetic hyperfine structures that are typical of amorphous, ferromagnetic alloys. All spectra were fitted using hyperfine field distribution $P\left(B_{\mathrm{hf}}\right)$ histograms. The corresponding $P\left(B_{\mathrm{hf}}\right)$ distributions are presented in Figs. 2a'-c'. The broad $P\left(B_{\mathrm{hf}}\right)$ distributions, ranging from about 10 to $34 \mathrm{~T}$, indicate the diversity of local atomic Fe environments in the amorphous structure. The average value of the hyperfine field of $23.0 \mathrm{~T}$ for the alloy containing $2 \%$ of cobalt increases to $24.0 \mathrm{~T}$ when $x=6$. The addition of cobalt to Fe-based amorphous alloys increases the strength of their average hyperfine fields [6]. A minor peak approximately between 10 and $11 \mathrm{~T}$ most likely originated from the presence of $\mathrm{B}$-rich environments. The shoulder above $30 \mathrm{~T}$, seen in the $P\left(B_{\mathrm{hf}}\right)$ distributions obtained from the CEMS spectra (Figs. 2b'-c'), is assigned to $\mathrm{Fe}(\mathrm{Co}, \mathrm{Ni})$ disordered regions on the surfaces. In general, the CEMS spectra of all studied as-quenched ribbons confirm the amorphous nature of the surface regions, however, they also identify small structural inhomogeneities on the surfaces, especially on the "air" side of the ribbons, where the quenching rate was the lowest. The D23 parameter, calculated as a ratio of the intensity of the second to the third lines of the discrete sextets used for fitting by the $P\left(B_{\mathrm{hf}}\right)$ distribution method, is 2.8 and 3.5-3.9 for the transmission and CEMS spectra, respectively. D23 values closer to 4 , as obtained for the CEMS spectra, indicate that the spins in the surface layers tend to align in the plane of the ribbons. This is directly related to rapid solidification of the ribbons as a result of melt spinning.

Examples of the Mössbauer spectra of the nanocrystalline alloys obtained after 1 hour of annealing at temperatures of $525^{\circ} \mathrm{C}$ and $550^{\circ} \mathrm{C}$ are shown for the $\mathrm{Fe}_{72} \mathrm{Co}_{6} \mathrm{Ni}_{2} \mathrm{Cu}_{1} \mathrm{Nb}_{3} \mathrm{Si}_{4} \mathrm{~B}_{12}$ alloy in Figs. 3 and 4 , 

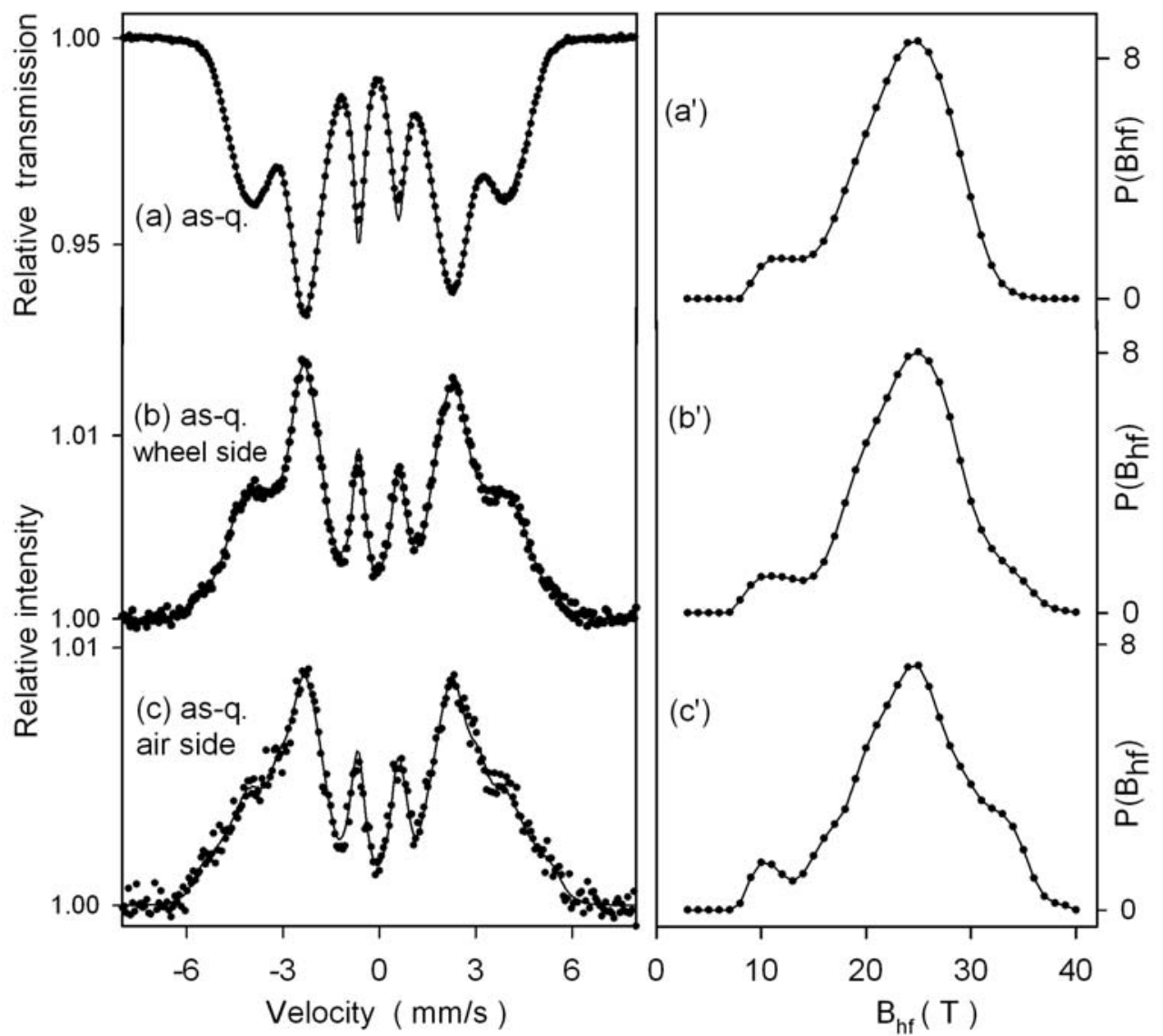

Fig. 2. (a) Transmission and (b-c) conversion electron Mössbauer spectra of the as-quenched $\mathrm{Fe}_{72} \mathrm{Co}_{6} \mathrm{Ni}_{2} \mathrm{Cu}_{1} \mathrm{Nb}_{3} \mathrm{Si}_{4} \mathrm{~B}_{12}$ alloy, and (a'-c') corresponding hyperfine field distributions, $P\left(B_{\mathrm{hf}}\right)$.

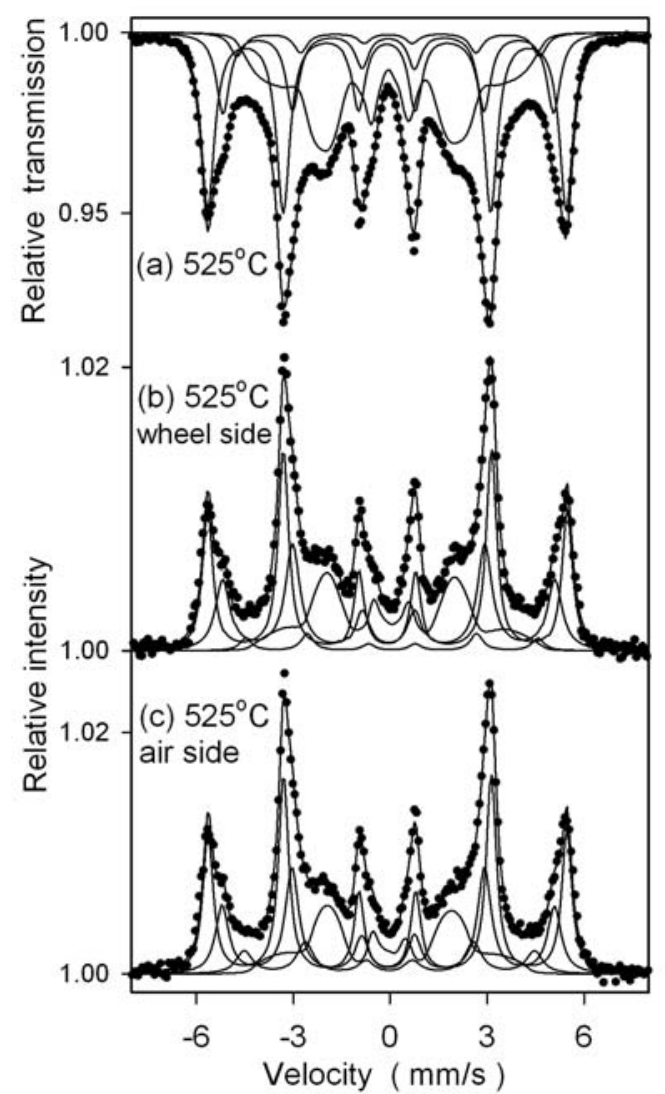

Fig. 3. (a) Transmission and (b-c) conversion electron Mössbauer spectra of the $\mathrm{Fe}_{72} \mathrm{Co}_{6} \mathrm{Ni}_{2} \mathrm{Cu}_{1} \mathrm{Nb}_{3} \mathrm{Si}_{4} \mathrm{~B}_{12}$ alloy annealed at $525^{\circ} \mathrm{C}$ for $1 \mathrm{~h}$.

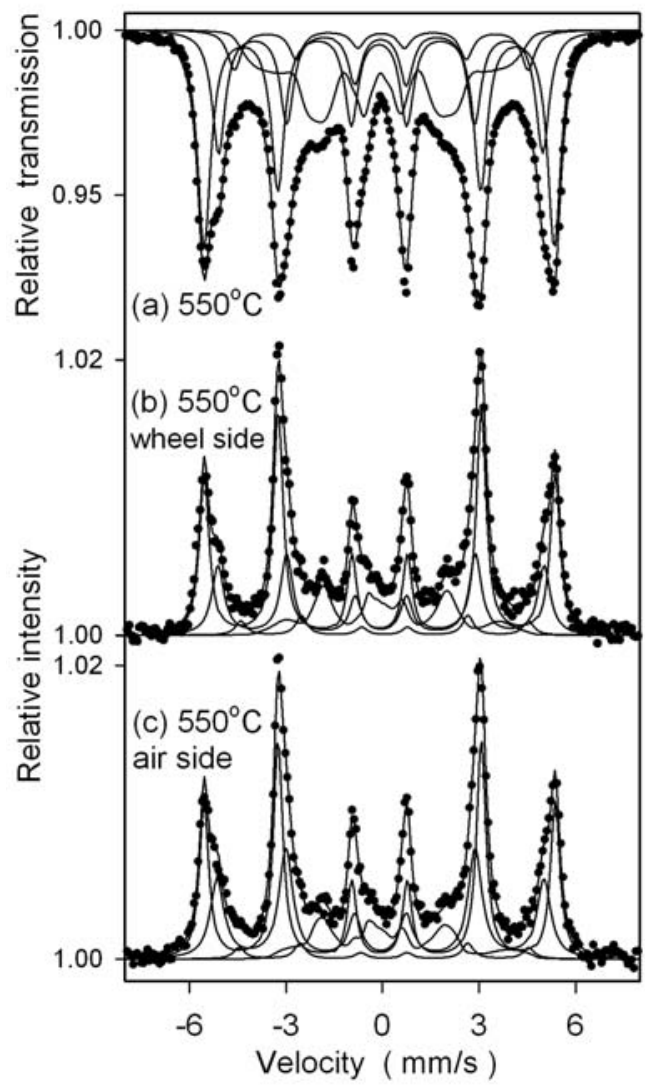

Fig. 4. (a) Transmission and (b-c) conversion electron Mössbauer spectra of the $\mathrm{Fe}_{72} \mathrm{Co}_{6} \mathrm{Ni}_{2} \mathrm{Cu}_{1} \mathrm{Nb}_{3} \mathrm{Si}_{4} \mathrm{~B}_{12}$ alloy annealed at $550^{\circ} \mathrm{C}$ for $1 \mathrm{~h}$ 
respectively. The transmission and CEMS spectra of all nanocrystalline alloys studied were fitted in the same way, i.e. using three discrete magnetic components with slightly broadened lines assigned to bcc Fe-based nanocrystallites, and a hyperfine field distribution component (a broadened sextet) corresponding to the remaining amorphous phase. The values of the discrete hyperfine fields, determined from the transmission and CEMS spectra for all nanocrystalline alloys studied, are within quite narrow ranges: $B_{\mathrm{hf} 1}=33.6-34.6 \mathrm{~T}, B_{\mathrm{hf} 2}=$ 31.1-31.9 T, $B_{\mathrm{hf} 3}=27.7-29.1 \mathrm{~T}$, depending on the composition of the alloy. These parameters, however, are independent of the annealing temperature. The values of the isomer shift are slightly larger than for $\alpha$-Fe foil. These hyperfine parameters, being quite different from those characteristic of pure bcc Fe $\left(B_{\mathrm{hf}}=32.95 \mathrm{~T}\right)$, indicate the formation of the bcc $\mathrm{Fe}(\mathrm{Co}, \mathrm{Ni}, \mathrm{Si})$ solid solution. The most abundant spectral component among three sextets attributed to the nanocrystalline phase is the one exhibiting $B_{\mathrm{hf1}}$, which is larger than $B_{\mathrm{hf}}$ of pure bcc Fe. Furthermore, the values of $B_{\mathrm{hf} 1}$ increase as Co content increases in the $\mathrm{Fe}_{80-x-y} \mathrm{Co}_{x} \mathrm{Ni}_{y} \mathrm{Cu}_{1} \mathrm{Nb}_{3} \mathrm{Si}_{4} \mathrm{~B}_{12}$ alloys. The hyperfine parameters indicate that this spectral component originates from bcc $\mathrm{Fe}(\mathrm{Co})$ regions. The sextets for $B_{\mathrm{hf} 2}$ and $B_{\mathrm{hf} 3}$ are assigned to bcc $\mathrm{Fe}(\mathrm{Ni}, \mathrm{Si})$ atomic environments and nanocrystals-amorphous matrix interfacial regions. The average hyperfine field related to the amorphous phase decreases to about $18-20 \mathrm{~T}$ as opposed to $23-24 \mathrm{~T}$ for the fully amorphous alloys, which is related to a significant change in the composition of the amorphous matrix due to partial crystallization of bcc $\mathrm{Fe}(\mathrm{Co}, \mathrm{Ni}, \mathrm{Si})$.

Visible changes in the Mössbauer spectra of the nanocrystalline alloys as a function of annealing temperature or when comparing transmission and CEMS spectra (Figs. 3 and 4) are related to fluctuations in relative fractions of the spectral components corresponding to the nanocrystalline phase and the amorphous matrix. The Mössbauer results obtained for $\mathrm{Fe}_{80-x-y} \mathrm{Co}_{x} \mathrm{Ni}_{y} \mathrm{Cu}_{1} \mathrm{Nb}_{3} \mathrm{Si}_{4} \mathrm{~B}_{12}$ alloys are summarized in Fig. 5 that presents the spectral fraction of the

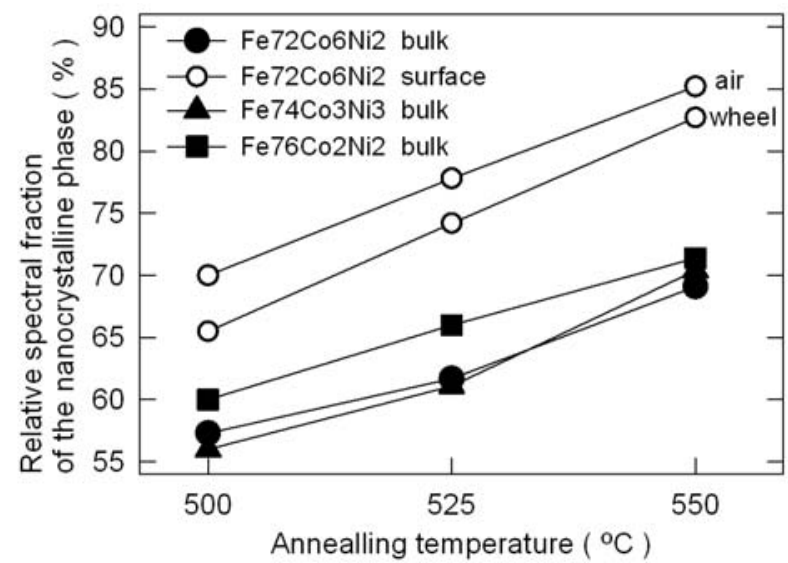

Fig. 5. Relative fraction of the crystalline phase vs. annealing temperature determined from the fittings of transmission Mössbauer spectra of the nanocrystalline $\mathrm{Fe}_{80-x-y} \mathrm{Co}_{x} \mathrm{Ni}_{y} \mathrm{Cu}_{1} \mathrm{Nb}_{3} \mathrm{Si}_{4} \mathrm{~B}_{12}$ alloys (filled symbols) and of the CEMS spectra of the alloy where $x=6$ and $y=2$ (empty circles). nanocrystalline phase (all three discrete sextets are taken into account), which increases gradually as annealing temperature increases at the expense of the amorphous phase fraction. The nanocrystalline fraction calculated from the transmission spectra is similar for the alloys annealed at the same temperatures. Significantly larger nanocrystalline fractions are observed for the surface layers (CEMS spectra) than in the volume of the ribbons as shown in Fig. 5 for the $\mathrm{Fe}_{72} \mathrm{Co}_{6} \mathrm{Ni}_{2} \mathrm{Cu}_{1} \mathrm{Nb}_{3} \mathrm{Si}_{4} \mathrm{~B}_{12}$ alloy. According to Mössbauer measurements differences in the relative fractions of the nanocrystallites between the volume and the surfaces of the ribbons originate from different quenching rates experienced by the surface and the inside parts of the ribbon during the melt-spinning process, causing compositional inhomogeneity across the thickness of the ribbon. Furthermore, the presence of more potential nucleation sites at the surfaces of the ribbons rather than internally is highly probable, which enhances the crystallization process in the surface layers.

The saturation magnetization values determined from vibrating sample magnetometer
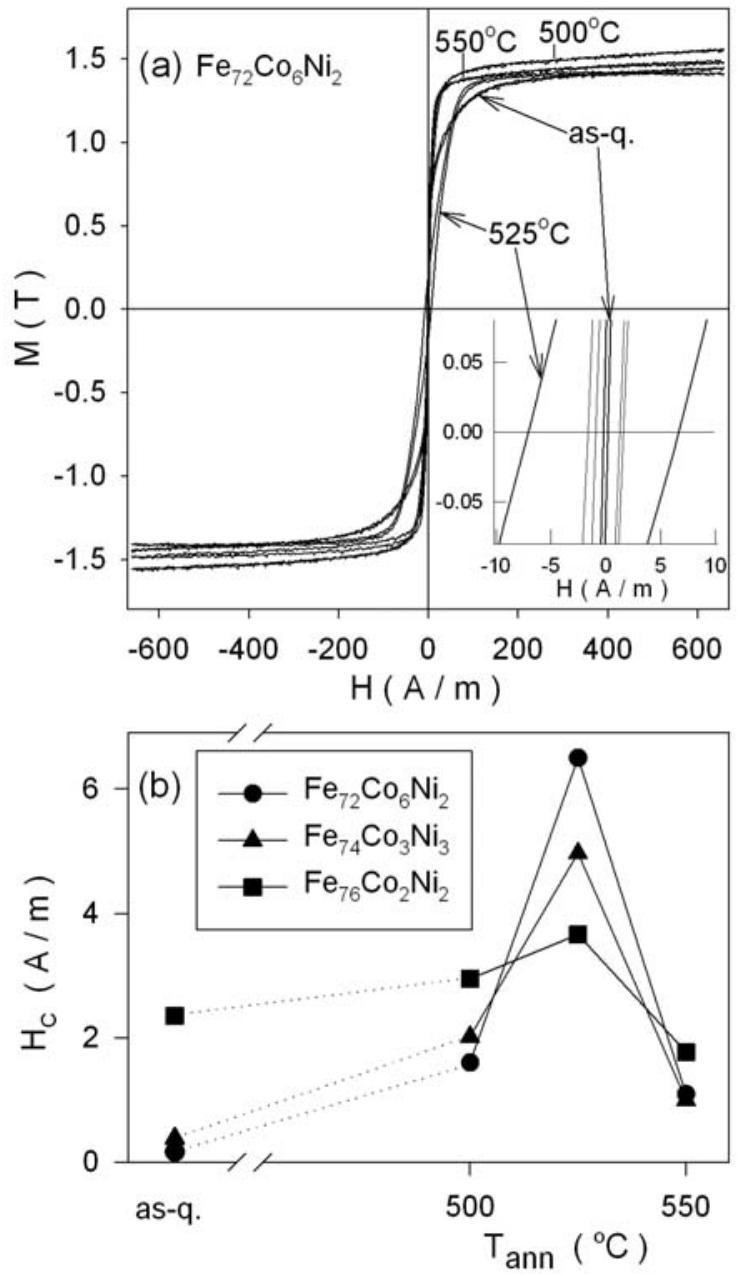

Fig. 6. (a) Hysteresis loops recorded for the $\mathrm{Fe}_{72} \mathrm{CO}_{6} \mathrm{Ni}_{2} \mathrm{Cu}_{1} \mathrm{Nb}_{3} \mathrm{Si}_{4} \mathrm{~B}_{12}$ alloy in the as-quenched and annealed states. The insert presents details of the central part of the loops. (b) Dependence of the coercive field on the annealing temperature of the nanocrystalline $\mathrm{Fe}_{80-x-y} \mathrm{Co}_{x} \mathrm{Ni}_{y} \mathrm{Cu}_{1} \mathrm{Nb}_{3} \mathrm{Si}_{4} \mathrm{~B}_{12}$ alloys. Values of the coercive field strength of the as-quenched amorphous alloys are also shown for comparison. 
(VSM) measurements are approximately 1.4 and $1.5 \mathrm{~T}$ for the amorphous and nanocrystalline $\mathrm{Fe}_{80-x-y} \mathrm{Co}_{x} \mathrm{Ni}_{y} \mathrm{Cu}_{1} \mathrm{Nb}_{3} \mathrm{Si}_{4} \mathrm{~B}_{12}$ alloys, respectively. All hysteresis loops recorded for the amorphous and nanocrystalline alloys studied reveal soft magnetic properties. As an example, the results obtained for the as-quenched and annealed $\mathrm{Fe}_{72} \mathrm{Co}_{6} \mathrm{Ni}_{2} \mathrm{Cu}_{1} \mathrm{Nb}_{3} \mathrm{Si}_{4} \mathrm{~B}_{12}$ samples recorded by the hysteresis loop tracer are presented in Fig. 6a. Changes in the coercive field strength, $H_{c}$, determined from these loops, are shown in Fig. $6 \mathrm{~b}$ as a function of the annealing temperature. Similar behaviour is observed for all nanocrystalline alloys studied. An increase in $H_{c}$ for annealing temperatures of up to $525^{\circ} \mathrm{C}$ is followed by a decrease for annealing at $550^{\circ} \mathrm{C}$. The increase in $H_{c}$ is caused by the precipitation of separated bcc nanocrystals, inducing internal stresses in the amorphous phase. As annealing temperature increases the volume fraction of nanograins becomes large enough to significantly decrease the distance between them, facilitating strong exchange coupling and the averaging out of the magnetocrystalline anisotropy [4]. For the alloys annealed at $550^{\circ} \mathrm{C}$, the relative fraction of the nanocrystalline components in transmission Mössbauer spectra is between 69 and $71 \%$ (Fig. 5). For FINEMET-like alloys, the nanostructures with volume fractions of nanocrystals of between 70 and $75 \%$ were reported to be practically non-magnetostrictive materials due to the compensation of the positive and negative magnetostriction contributions of the amorphous and FeSi nanocrystalline phases, respectively [5]. In the case of the nanocrystalline $\mathrm{Fe}_{80-x-y} \mathrm{Co}_{x} \mathrm{Ni}_{y} \mathrm{Cu}_{1} \mathrm{Nb}_{3} \mathrm{Si}_{4} \mathrm{~B}_{12}$ alloys studied herein, the bcc nanograins exhibit a more complex atomic environment than in FINEMET-like alloys, which might be responsible for fluctuations in magnetocrystalline and magnetoelastic anisotropies, affecting the coercivity of the alloys. For example, it was shown that the bcc Fe phase with small additions of $\mathrm{Co}$ or $\mathrm{Ni}$ is characterized by a small degree of negative saturation magnetostriction [7]. When the content of the alloy consists of about $6 \%$ Co the magnetostriction becomes zero and even positive for larger contents [7]. Noticeable differences in $H_{c}$ between the nanocrystalline alloys are observed for annealing at $525^{\circ} \mathrm{C}$ (Fig. 6b), which are most probably related to structural differences, depending on the alloy composition and especially Co content. It is worth noting that a similar local peak in the $H_{c}$ dependence on the annealing temperature was found, e.g. in nanocrystalline $\mathrm{Fe}_{80.5} \mathrm{Nb}_{7} \mathrm{~B}_{12.5}$ [8] or $\mathrm{Fe}(\mathrm{Co}) \mathrm{SiBPCu}$ alloys $[9,10]$. The authors suggested a major role of intergranular exchange coupling among the nanograins with regard to the low magnetostriction effect as far as the contribution to the coercive field variation is concerned [9]. It was also concluded that low Co concentrations of up to about 5 at.\% are effective in reducing the coercive field strength by decreasing both grain size and magnetostriction [10].

\section{Conclusions}

The as-quenched $\mathrm{Fe}_{80-x-y} \mathrm{Co}_{x} \mathrm{Ni}_{y} \mathrm{Cu}_{1} \mathrm{Nb}_{3} \mathrm{Si}_{4} \mathrm{~B}_{12}$ alloys $(x=2,3$ and 6 at.\%, and $y=2$ and 3 at.\%) were generally amorphous in volume with some minor bcc inclusions in the surface layers. The structure of the samples annealed at temperatures of between 500 and $550^{\circ} \mathrm{C}$ for $1 \mathrm{~h}$ consisted of the nanocrystalline bcc $\mathrm{Fe}(\mathrm{Co}, \mathrm{Ni}, \mathrm{Si})$ solid solution and the remaining amorphous phase. According to fitting of the Mössbauer spectra, the relative spectral fractions calculated for the nanocrystalline phase increased from 56-60\% after annealing at $500^{\circ} \mathrm{C}$ and to $69-71 \%$ after annealing at $550^{\circ} \mathrm{C}$. It was revealed that on both surfaces ("air" and wheel sides) of the annealed ribbons the phase composition was qualitatively the same as in the volume, however, a considerably larger fraction of the nanocrystalline phase was formed in the surface layers. All studied amorphous and nanocrystalline alloys exhibited good soft magnetic properties. The saturation magnetization of nanocrystalline $\mathrm{Fe}_{80-x-y} \mathrm{Co}_{x} \mathrm{Ni}_{y} \mathrm{Cu}_{1} \mathrm{Nb}_{3} \mathrm{Si}_{4} \mathrm{~B}_{12}$ alloys is about 1.5 T, which is larger than that of FINEMET alloys but somewhat smaller than that of NANOPERM ones. It is predicted that by eliminating $\mathrm{Ni}$ addition, the degree of saturation magnetization would increase. Magnetic softening of the nanocrystalline alloys was observed after annealing at $550^{\circ} \mathrm{C}\left(H_{c}=1.0-1.7 \mathrm{~A} / \mathrm{m}\right)$. For these alloys the relative spectral fraction of the Fe-based nanocrystals embedded in the amorphous matrix reached $69-71 \%$, ensuring strong exchange coupling between the bcc nanograins combined with a significant reduction in the contribution of magnetocrystalline and magnetoelastic anisotropies to the total magnetic anisotropy of the samples.

\section{References}

1. Hasegawa, R. (2012). Advances in amorphous and nanocrystalline materials. J. Magn. Magn. Mater., 324(21), 3555-3557. DOI: 10.1016/j jmmm.2012.02.088.

2. Yoshizawa, Y., Oguma, S., \& Yamauchi, K. (1988). New Fe-based soft magnetic alloys composed of ultrafine grain structure. J. Appl. Phys., 64(10), 6044-6046. DOI: 10.1063/1.342149.

3. Suzuki, K., Makino, A., Kataoka, N., Inoue, A., \& Masumoto, T. (1991). High saturation magnetization and soft magnetic properties of bcc Fe-Zr-B and Fe-Zr-B-M ( $\mathrm{M}=$ transition metal) alloys with nanoscale grain size. Mater. Trans. JIM, 32(1), 93-102. DOI: $10.2320 /$ matertrans1989.32.93.

4. Herzer, G. (1993). Nanocrystalline soft magnetic materials. Phys. Scripta, T49, 307-314. DOI: 10.1088/0031-8949/1993/T49A/054.

5. Kulik, T., Vlasák, G., \& Żuberek, R. (1997). Correlation between microstructure and magnetic properties of amorphous and nanocrystalline $\mathrm{Fe}_{73.5} \mathrm{Cu}_{1} \mathrm{Nb}_{3} \mathrm{Si}_{16.5} \mathrm{~B}_{6}$. Mater. Sci. Eng. A, 226/228, 701-705. DOI: 10.1016/ S0921-5093(97)80074-3.

6. Kopcewicz, M., Grabias, A., \& Latuch, J. (2011). Magnetic properties of $\mathrm{Fe}_{80-x} \mathrm{Co}_{x} \mathrm{Zr}_{7} \mathrm{Si}_{13}(x=0-30)$ amorphous alloys. J. Appl. Phys., 110(10), 103907. DOI: $10.1063 / 1.3658851$. 
7. Couderchon, G., \& Thiers, J. F. (1982). Some aspects of magnetic-properties of $\mathrm{Ni}-\mathrm{Fe}$ and Co-Fe alloys. J. Magn. Magn. Mater., 26(1/3), 196-214. DOI: 10.1016/0304-8853(82)90152-4.

8. Kopcewicz, M., Grabias, A., Škorvánek, I., Marcin, J., \& Idzikowski, B. (1999). Mössbauer study of the magnetic properties of nanocrystalline $\mathrm{Fe}_{80.5} \mathrm{Nb}_{7} \mathrm{~B}_{12.5}$ alloy. J. Appl. Phys., 85(8), 4427-4429. DOI: 10.1063/1.370363.
9. Zhang, Z., Sharma, P., \& Makino, A. (2012). Role of $\mathrm{Si}$ in high $\mathrm{B}_{\mathrm{s}}$ and low core-loss $\mathrm{Fe}_{85.2} \mathrm{~B}_{10-x} \mathrm{P}_{4} \mathrm{Cu}_{0.8} \mathrm{Si}_{x}$ nano-crystalline alloys. J. Appl. Phys., 112(10), 103902-1-103902-8. DOI: 10.1063/1.4765718.

10. Zhang, Y., Sharma, P., \& Makino, A. (2014). Effects of cobalt addition in nanocrystalline $\mathrm{Fe}_{83.3} \mathrm{Si}_{4} \mathrm{~B}_{8} \mathrm{P}_{4} \mathrm{Cu}_{0.7}$ soft magnetic alloy. IEEE Trans. Magn., 50(4), 2003004. DOI: 10.1109/TMAG.2013.2286617. 